\title{
INDEFATIGABLE WILLINGNESS TO ACCOMPLISH OBJECTIVES: THE RELATIONSHIP BETWEEN EFL LEARNERS' MOTIVATION AND AUTONOMY
}

\author{
${ }^{1}$ Fatemeh Khonamri, ${ }^{2}$ Khazar Molana, ${ }^{2}$ Marzie Danaei, \& ${ }^{3}$ Mohammad Kazemian \\ Sana'ati \\ ${ }^{1}$ Assistant Professor, Faculty of Humanities, University of Mazandaran, Babolsar, Iran \\ ${ }^{2}$ Faculty of Foreign Languages, Islamic Azad University Research and Science branch, \\ Tehran, Iran \\ ${ }^{3}$ English Lecturer, Faculty of Medicine, Guilan University of Medical Sciences, Rasht, Iran \\ Corresponding Author Email: m_kazemiansanati@yahoo.com
}

\begin{tabular}{l}
\hline \hline Article Info \\
Article History \\
Received: September 2020 \\
Revised: September 2020 \\
Published: October 2020 \\
\hline Keywords \\
Motivation; \\
Autonomy; \\
Intrinsic motivation;
\end{tabular}

Intrinsic motivation;

\begin{abstract}
The common widespread interest in the socio-cultural aspect of language learning among applied linguists has made ESL researchers draw attention to learners' motivation and autonomy in the European and Asian educational circles. The rationale of this study is to pinpoint the relationship between EFL learners' motivation and autonomy. To gather relevant data, motivation and autonomy questionnaires were distributed among 100 EFL learners, who were chosen through Quick Placement Test (QPT), and were put them into B2, C1, and C2 levels of linguistic proficiency based on Common European Framework Rubric (CEFR) model. To fulfill the objectives of this study, both descriptive and inferential statistics were utilized in the process of data analysis. Regarding the statistical analysis, learners' motivation significantly correlated with their autonomy. Additionally, it was found that there was a significant positive correlation between autonomy and intrinsic motivation, while the correlation between autonomy and extrinsic motivation was significant but negative. This study can shine a light on language teaching in general and in particular on the relationship between EFL learners' motivation and autonomy.
\end{abstract}

How to cite: Khonamri, F., Molana, K., Danaei, M., Kazemian, M. (2020). Indefatigable willingness to accomplish objectives: The relationship between EFL learners' motivation and autonomy. JOLLT Journal of Languages and Language Teaching, 8(4), 422-431. DOI: https://doi.org/10.33394/jollt.v\%vi\%i.2960

\section{INTRODUCTION}

The privileged position of applied linguistics in modern linguistic sciences is axiomatic (Kvapil\& Siposova,2020) and motivation is one of the hot-button issues in psycholinguistics. The growing interest in the socio-cultural dimension of language learning among applied linguists has made ESL researchers turn their attention to learners' motivation and autonomy in classroom settings in a number of European and Asian countries. On the other hand, a meta-analysis of motivation studies has identified motivation as the key to success in learning a foreign or second language (Gardner, 1990; Masgoret \& Gardner, 2003). Nevertheless, motivating students is seen by teachers as one of the most serious sources of difficulty (Dörnyei, 2001) in the classroom. Ushioda (2008) stated that the review of the recent important academic works in motivation education research indicates that the importance of motivation's social dimension has increased eye-catchingly. Moreover, autonomy is found to be "more closely related to motivational factors than to performance and ... seem(s) to foster intrinsic goal orientation, task value, and self-efficacy, all of which are critical components of continuing motivation" (Garcia \&Pintrich, 1996, p. 477). Many writers have concluded that it 
is the autonomy that leads to motivation. A strong link between motivation and autonomy can be observed in Deci and Ryan (1985) work into intrinsic motivation. The 'ten commandments' for motivating language learners proposed by Dörnyei and Csizér (1998) also imply that motivation is a result of learner autonomy since their seventh 'commandment' to teachers seeking to motivate students is to promote learner autonomy. For these writers, autonomy leads to motivation, which in turn leads to greater success in language learning. Since autonomy and motivation in foreign language learning are context-specific and perceived differently in different cultures, examining the relationship between Iranian EFL learners' motivation and autonomy drew the researchers' attention.

On the other hand, in most studies on motivation in English as a Foreign Language (EFL) context, there was a strong emphasis on its relationship to language learning achievement (Dörnyei \& Ushioda, 2013). Nevertheless, relatively little research has focused on the link between motivation and learning autonomy (Z. Ma \& R. Ma, 2012; M. C. Cheng \& T. P. Cheng, 2013), and almost no studies have attempted to explore the predictive nature of motivation for autonomy to occur. This is especially important for EFL learners who have no or very limited exposure to English for real purposes and must often work harder and more independently to learn the language more efficiently. As a result, for EFL learners, autonomy is a door to learn the target language better (Najeeb, 2013). Building on Spratt et al. (2002) who argued that autonomy and motivation are two elements that interact closely in the language learning process, the present study explored the relationship between motivation and autonomy in 100 intermediate, upper-intermediate and advanced EFL learners in a language institute in Iran. The study's primary purpose is to examine how different types and elements of motivation correlated with autonomy. While there is a wealth of studies on autonomy, more novel studies must emerge to shed further light on the promotion of autonomous language learning strategies and the role that motivation can play in this regard.

\section{Motivation}

Motivation is defined in various ways by different researchers, but they seem to agree that motivation is responsible for determining human behavior by energizing it and giving it direction. In general motivation is the driving force in any situation that leads to action. What most scholars seem to agree is that motivation is one of the key factors that influence the rate and success of second/foreign language learning. Many scholars highlight the importance of motivation in learning as it can affect what, when, and how we learn (Pintrich \& Schunk, 2002). Brown (2000) stated that connecting the success of a language learner to the proper motivation is an easy claim in second language learning. With similar views, Gardner (2006) posited that higher levels of motivation among learners in comparison with lower level will lead to the more successful language learning process. As a general rule, high school students had considerably high L2 motivation than secondary school students regarding their general English language proficiency owing to the influencing of peers (Isatayeva, Smanov, Mutanova, Aytbayeva, Saduova, Beissembayeva, 2018). Accordingly, Intrinsic motivation is defined as motivation to involve in an activity because that activity is enjoyable and satisfying to do (Deci \& Ryan, 1985) whereas extrinsic motivation refers to actions carried out to attain some instrumental end such as earning a reward or avoiding a punishment.

\section{Autonomy}

In the domain of foreign language learning it was Holec's (1981) seminal study Autonomy and foreign language learning which developed a growing interest in the concept of "learner autonomy" in the last three decades. Holec (1981) defined learner autonomy as an acquired ability naturally or through formal learning to take change of a learner's learning.Furthermore, Penaflorida (2002) described it as a kind of needs analysis for the purpose of selecting and applying suitable strategy which ultimately cause impressive 
learning management. More than this, Dickinson (1987) clarified autonomous context as a situation which learner is fully responsible for making and implementing all decisions related to his/her learning where there is no role for teacher or institute.Nunan (1997) believed that the autonomous learner, operates independently of classroom, teacher or textbook.

Sanprasert (2010) opined that learning autonomy can be acquired and inspired by formal education. Language teachers can ameliorate their learners' autonomy by means ofproper training that emboldens students to work autonomously.As Little (2007) and Snodin (2013) believed, learning autonomy is not innate, but demands support from others and practice. Chan (2003) suggested that autonomy "grows out of the individual's acceptance of his or her own responsibility for learning" (p. 33).Recently, the results of a study conducted by Spratt, Humphries and Chan (2002) have proposed that the 'relationship between motivation and autonomy works in both directions, changing in direction with different stages in a learner's progress and in learners' lives in general" (Spratt et al., 2002, p. 262). They believe that the relationship between autonomy and motivation is not always one in which autonomy leads to motivation.

The findings of another study conducted by Vaezi (2008) revealed that Iranian students are instrumentally motivated and they are highly integrative too. The results revealed that instrumental and integrative goals, especially future career development, meeting different walks of life and learning English in order to use the Internet properly are very crucial for Iranian students. The main objectives of another study conducted by Hashemian and Heidari Soureshjani (2011) were to explore the possible relationship among learner autonomy, academic performance, and motivation. The study first revealed that there was a positive and significant relationship between autonomy and GPA. The study also indicated a positive and significant relationship between motivation and GPA. As to the relationship between motivation and autonomy, the study revealed a positive but no significant interplay. The results of another study conducted by Jafari (2002) revealed that the use of authentic materials has a great impact on the motivation of EFL learners. It is also found that gender does not make a significant difference in the motivation of the subjects on the study. The results of a study conducted by Hosseini Fahraji (2004) indicated that due to a flexible syllabus, highly motivating research topics and the interactions in the complex dynamic classroom environment, learners do take responsibility for most aspects of learning and thus the complexity theory/process-based syllabus design proves to be a promising approach for autonomy developing.Swan(2016) examined the relationship between autonomy and motivation on 76 Libyan University English majors via two piloted questionnaires. The results indicated that the more motivated the students are, the more independent they are. That is, motivation and autonomy reinforce each other with one another. Selivanova, Gramova, Mashkin(2018) studied improving student motivation for learning the second foreign language in Russia. The results revealed that individual support, teacher's assistance and support of a student could ameliorate school children motivation for the second foreign language learning.

Based on the above-mentioned purpose, are the researchers sought to investigate the answer to the following research questions:

1. Is there any significant relationship between EFL learners' motivation and autonomy?

2. Is there any significant relationship between EFL learners' intrinsic motivation and autonomy?

3. Is there any significant relationship between EFL learners' extrinsic motivation and autonomy? 


\section{RESEARCH METHOD}

The participants were one-hundred EFL learners at two branches of Hermes Espinas Iranian Language School in Tehran, Iran. Two-hundred learners in this study were screenedvia Quick Placement Test (QPT). Out of two-hundred learners,one-hundred of them were diagnosed as B2, C1, C2 based on Common European Framework Rubric (CEFR) model, whose age rangeswere from 15 to 40 years of age. Due to the access of one of the researchers to the female centers of Hermes Espinas Iranian Language School, only female students participated in the study. Among the participants, 82 students were at B2 and C1 levels while only 18 learners were at $\mathrm{C} 2$ level.

\section{Instruments}

In order to gather the required data two questionnaires were employed: A Motivation Questionnaire and a Learner Autonomy Questionnaire. As to the first questioner, a Motivation questionnaire developed by Lepper, Corpus, and Iyengar (2005), which incorporates 30 items on a five-point Likert scale was employed. This scale measured both intrinsic and extrinsic motivation. Items 1 to 17 assessed intrinsic motivation, whereas items 18 to 30 measured extrinsic motivation. The second one was the Learner Autonomy Questionnaire developed by Zhang and Li (2004, p.23), which has two sections. The first part includes 11 items with corresponding 5-point Likert scale response choices ranging from A (never) to E (always), and the second part consisting of 10 multiple-choice items with alternatives on a five-point scale (A to E).

\section{Procedure}

The time allocated to complete these two questionnaires was 10 minutes each. At the time of administration, the researcher was always present to help the respondents if necessary and ensure confidential and independent responses.

\section{Data Analysis}

In order to be able to analyze the obtained data, the researchers run both descriptive and inferential statistics. For descriptive statistics, mean, standard deviation, standard error of the mean, and skewness ratios of each set of scores were obtained. Moreover, the researchers computed the internal consistency or reliability of each questionnaire through Cronbach Alpha. Finally, to be able to test the null hypotheses of the study, the researchers conducted Pearson Correlation, and Spearman Correlation.

\section{RESEARCH FINDINGS AND DISCUSSION Research Findings}

The details of data analyses for the ultimate purpose of testing the null hypotheses of the study are provided and discussed below in a chronological order. The first step in data analysis comprised of estimating the descriptive statistics of the motivation and autonomy questionnaires. The mean of total motivation scores, intrinsic motivation scores and extrinsic motivation scores turned out to be 96.8, 63.3 and 33.47 respectively. Moreover, the distribution of the total motivation scores and total intrinsic motivation scores turned out to be normal as the skewness ratios fell within the acceptable range of \pm 1.96 . However, the distribution of total extrinsic motivation scores did not observe normalcy with a skewness ratio of 4.48. The researchers also computed the reliability of the motivation questionnaire through Cronbach's Alpha. The reliability estimates of the total motivation questionnaire with 30 items turned out to be .659 , but the alpha for the intrinsic and extrinsic motivation turned out to be .88 and .85 respectively. Since the distribution of the extrinsic motivation scores demonstrated a significantly positive skewness, Spearman correlation was run among the 
three variables; namely total motivation, intrinsic motivation, and extrinsic motivation scores. The results are shown in Table. 1 below.

Table. 1

Correlations among the Subsections and Total Motivation Questionnaire

\begin{tabular}{lllll}
\hline & & \multicolumn{1}{c}{$\begin{array}{c}\text { Total } \\
\text { Motivation }\end{array}$} & $\begin{array}{c}\text { Total Extrinsic } \\
\text { Motivation }\end{array}$ & $\begin{array}{c}\text { Total Intrinsic } \\
\text { Motivation }\end{array}$ \\
\hline Total Motivation & $\begin{array}{l}\text { Correlation } \\
\text { Coefficient }\end{array}$ & 1.000 & $.336^{* *}$ & $.729 *$ \\
\cline { 2 - 5 } & Sig. (2-tailed) &. & .001 & .000 \\
\cline { 2 - 5 } & $\mathrm{N}$ & 100 & 100 & 100 \\
\hline Total Extrinsic Motivation & $\begin{array}{l}\text { Correlation } \\
\text { Coefficient }\end{array}$ & $.336 *$ & 1.000 & $-.325^{* *}$ \\
\cline { 2 - 5 } & Sig. (2-tailed) & .001 &. & .001 \\
\hline Total Intrinsic Motivation & $\mathrm{N}$ & 100 & 100 & 100 \\
\hline
\end{tabular}

**. Correlation is significant at the 0.01 level (2-tailed).

As shown in Table.1, the correlation between total motivation and intrinsic motivation turned out to be positive and significant $(\mathrm{r}=.729, \mathrm{df}=100, p=.0005<.01)$. The correlation between total motivation and extrinsic motivation also turned out to be positive and significant $(\mathrm{r}=.336, \mathrm{df}=100, p=.001<.01)$. These results, demonstrated that intrinsic motivation had a higher correlation with the total motivation score compared to the extrinsic motivation (.729 vs. .336), despite the fact that the two correlations were significant. However, as Table 4.1 illustrates, the correlation between intrinsic and extrinsic motivation came out to be negative and significant $(\mathrm{r}=-.325 \mathrm{df}=100, p=.001<.01)$. This could be a source of evidence for the validity of the questionnaire as both subcategories correlated positively and significantly with the total questionnaire result, while the two subcategories representing different sources of motivation (i.e., extrinsic and intrinsic) demonstrated significant but negative correlation. This logically indicates that more extrinsic incentives for behavior among the learners correspond with less internal incentives for that behavior.

The descriptive statistics of the Autonomy Questionnaire were computed for the 100 participants of the study as the next step. The mean score of the autonomy questionnaire turned out to be 72.07 and the distribution demonstrated normalcy as the skewness ratio fell within the acceptable range of \pm 1.96 . The reliability of Autonomy Questionnaire turned out to be .63 for 21 items.To test the null hypothesis, the researchers needed to run Pearson correlation, the assumptions of which had to be checked a priori. Table. 2 below demonstrates the result of the Pearson correlation ran between the motivation and autonomy scores. The data demonstrated a significant linear correlation between the two variables $(r=.272, d f=100$, $p=.006<.01$, two-tailed).

Table. 2

Pearson Correlations between Autonomy and Motivation Scores

\begin{tabular}{lcc}
\hline & Total Autonomy & Total Motivation \\
\hline Pearson Correlation & 1 & $.272^{* *}$ \\
\hline Sig. (2-tailed) & & .006 \\
\hline $\mathrm{N}$ & 100 & 100 \\
\hline Total Motivation & Pearson Correlation & $.272^{* *}$ \\
\hline
\end{tabular}




\begin{tabular}{ccc}
\hline Sig. (2-tailed) & .006 & \\
\cline { 2 - 3 } $\mathrm{N}$ & 100 & 100 \\
\hline **. Correlation is significant at the 0.01 level (2-tailed). & \\
\hline
\end{tabular}

As the result, the researchers were able to reject the first null hypothesis that stated "there is no significant relationship between EFL learners' motivation and autonomy".To test the second and third null hypotheses which assumed no significant relationship between autonomy and intrinsic and extrinsic motivation, the same assumptions had to be checked for Pearson Correlation. The results are demonstrated in Table3 below.

Table 3

Spearman Correlations between Autonomy and Extrinsic and Intrinsic Motivation

\begin{tabular}{llccc}
\hline & & Total Autonomy & $\begin{array}{c}\text { Total Intrinsic } \\
\text { Motivation }\end{array}$ & $\begin{array}{c}\text { Total Extrinsic } \\
\text { Motivation }\end{array}$ \\
\hline \multirow{2}{*}{ Total Autonomy } & Correlation Coefficient & 1.000 & $.467^{* *}$ & $-.213^{*}$ \\
\cline { 2 - 5 } & Sig. (2-tailed) &. & .000 & .034 \\
\cline { 2 - 5 } & $\mathrm{N}$ & 100 & 100 & 100 \\
\hline **. Correlation is significant at the 0.01 level (2 tailed). & & \\
\hline
\end{tabular}

Based on Table 4.3, a significant positive correlation was found between autonomy and intrinsic motivation $(\mathrm{r}=.467, \mathrm{df}=100, p=.0005>.01$, two-tailed). Therefore, the researchers were able to reject the second null hypothesis that stated "there is no significant relationship between EFL learners' intrinsic motivation and autonomy". Table 4.3 also demonstrates a significant but negative correlation between autonomy and extrinsic motivation $(\mathrm{r}=-.213, \mathrm{df}=$ $100, p=.034<.05$, two-tailed). Therefore, the researchers were able to reject the third null hypothesis that stated "there is no significant relationship between EFL learners' extrinsic motivation and autonomy".

\section{Discussion}

The results of the study indicated that there was a significant relationship between motivation and autonomy. In other words, the more the learners are motivated, the higher the probability that they are autonomous. This significant positive relation is in line with the findings of many previous studies concerning the significant role motivation plays in the ultimate success of language learners in the challenging process of language learning and developing their autonomy. In their study, Wang and Palincsar (as cited in Januin, 2007) found a positive relationship between being responsible for learning and motivation. They showed that putting responsibility on the shoulders of L2 learners and making them able to choose their goals independently will increase their motivation and they can achieve their goals better. However, the study of Hashemian and Heidari Soureshjani (2011) showed a positive but non-significant interplay between motivation and autonomy of L2 learners in a distant context. Their study was conducted among 60 L2 learners from Shahrekord Payam-eNoor University majoring in English Translation. The results are consistent with many previously reported results, such as those by and Shearin (1994) and Ushioda (1996), that motivation plays a significant role in effectively learning a target language. Students probably will not become autonomous learners if they are unmotivated (Fazey \& Fazey, 2001; Fukuda, Sakata, \& Takeuchi, 2011). Moreover, it is in line with Swan's (2016), that is, the more 
motivated the students are, the more independent they are. Additionally, it is consistent with Isatayeva et al.'s (2018) seniority has a higher motivation and autonomy.

The reason that the findings of their study came out to be different from the findings of the current study might be due to the fact that their students were most probably at a higher level of proficiency compared to the participants of this study as they were students of English Translation while the participants of the present study were B2, C1, and C2 language learners of Hermes language school. In this study, the intrinsic motivation section of the Motivation Questionnaire (Lepper et al., 2005) comprised three parts: challenge, curiosity, and independent mastery. Items 1-5 examined the learners' 'challenge', while items 6-11 kept a record of learners' 'curiosity'. The subcategory of 'independence mastery' was measured through items 12-17. These subcategories conceptually bear more connection to the concept of autonomy as it is clear through the examples of the items as follows:

Item 1: I like hard work because it's a challenge.

Item 7: I ask questions in class because I want to learn new things.

Item 13: I like to try to figure out how to do assignments on my own. (See Appendix A for the rest of the items)

As it is obvious, such characteristics mentioned in the intrinsic motivation section of the questionnaire are conceptually those applied to more autonomous learners. On the other hand, the extrinsic motivation section has three subscales: easy work, pleasing the teacher, and most important of all 'dependence on the teacher.' Items 18-22 assess the 'easy work', for example: 'I don't like to figure out difficult problems.' In addition, items 23-25 represent the 'pleasing the teacher' subcategory, for example: 'I read things because the teacher wants me to.' Finally, items 26-30 assess the 'dependence on teacher,' for example: 'I like to have the teacher help me with my schoolwork/assignments.' According to the findings of the study and the concepts of the items in the extrinsic section of the Motivation Questionnaire (Appendix A), one can find out that extrinsic motivation is a motive for learning which rather than being internal to the learner is external to him/her and one very strong external source to motivate learners is the teacher, which will, in turn, result in more dependence upon the teacher and less autonomy. Therefore, extrinsic motivation has a negative correlation with autonomy because the more the learners are extrinsically motivated, the more they rely on the teacher, and the less they are autonomous.

In this case, the findings of this study are in line with the results of the study conducted by Chang (2004) on 307 English majors in Taiwanese colleges, which indicated a significant correlation between learners' motivation and learning strategies. The findings have also shown that intrinsic motivation played an important role in enhancing second language learning. Extrinsic motivation, on the other hand, was found significantly but negatively correlated with cognitive strategies. The results of another study conducted by Jorge Bravo et al. (2017) approved the existence of the cyclical interaction between 'autonomy and motivation' in which the levels of motivation related to the frequency of occurrence of autonomous language learning activities were conducted by undergraduate students were examined. Another study conducted by Liu (2015) also aimed to investigate the learner autonomy of EFL students in Taiwan and the role motivation played in influencing the construct. The main findings indicated that students seemed to have a satisfactory sense of responsibility for their own learning, and there were significant differences in all the dimensions of autonomy at different motivation levels. With stronger motivation, students were able to achieve a higher level of autonomy. Furthermore, in this study, motivation and autonomy were highly positively correlated as motivation contributed to half of the variance 
in autonomy, serving as a strong predictor for and an indispensable factor influencing the degrees of learner autonomy.

All in all, the results obtained from the present study led to the conclusion that motivation and autonomy as influential factors in the process of learning a target language were significantly correlated. As a result, it is proven that enhanced motivation is conditional to the promotion of learner autonomy. The motivation of learners can be increased with some training programs which aim to help students reduce their dependence on their teachers and take responsibility for their own learning, be able to control their own learning, and attribute their success and failure to their own efforts rather than outside factors, develop abilities for goal-setting and planning and build feelings of self-confidence.

\section{CONCLUSION}

The main concern of this study was to investigate the relationship between EFL learners' motivation and autonomy, which are assumed to be important aspects of second language learning. The results of the study showed that there is a significant relationship between motivation and autonomy. Furthermore, in this study, a significant positive correlation was found between autonomy and intrinsic motivation, whereas it was revealed that there is a significant but negative correlation between autonomy and extrinsic motivation. This outcome of the research supports the study by Cotterall (1999), who asserted that motivation can be an antecedent factor of successful autonomous learning.

Enhancing students' motivation may help them achieve more in the English language learning process as it is highly correlated with their level of autonomy. Therefore, this study implies that teachers have an important role in developing the motivation and autonomy of language learners and they should take language learners' motivation into consideration in order to train them to be more autonomous. By measuring learner autonomy and motivation at the beginning of each semester in any educational context, L2 teachers may make L2 learners aware of these two important features and the degree to which they possess them and thus make them more responsible for their own learning. This implication is in line with what Fumin and Li (2012) stated that in order to improve students' autonomous learning ability, teachers should offer proper guidance to students in regulating their own study and provide them explicit instructions on the strategies for learner autonomy so that they can be responsible for their own study.This implication is in line with what Deci, Koestner, and Ryan (2001) suggested that instead of focusing on rewards for motivating students' learning, it is crucial to focus more on how to facilitate intrinsic motivation, for example, by beginning from the students' perspective to develop more interesting learning activities, to offer more options, and to ensure that tasks are optimally challenging.

To sum up, the present study can be replicated with larger samples, various levels of language proficiency, and different genders and age groups. The researchers hope the results obtained from the present study will be useful for those involved in language teaching, curriculum development, and assessment to help language learners improve their motivation, specifically intrinsic motivation and autonomy.

\section{REFERENCES}

Bravo, J.C \&. Intriago, E. A \& Holguín, J.V. \& Garzon G.M \& Arcia, L.O (2017). Motivation and Autonomy in Learning English as Foreign Language: A Case Study of Ecuadorian College Students English Language Teaching; 10(2), 9-11.

Brown, H. D. (2000). Principles of language learning and teaching. New Jersey: Prentice Hall. 
Chan, V. (2003). Autonomous language learning: The teachers' perspectives. Teaching in Higher Education, 8(1), 33-54.

Chang, H. H. (2004). The relationship between extrinsic/intrinsic motivation and language learning strategies among college students of English in Taiwan. Unpublished master's thesis, Ming Chuan University, Taiwan.

Cheng, M. C., \& Cheng, T. P. (2013). Reflections of the Role of Motivation on Learning English for Successful College EFL Learners in Taiwan. World Journal of Education, 2(5), 8- 14.

Cotterall, S. (1999). Key variables in language learning: What do learners believe about them? System 27(1) 493-513.

Deci, E. L., \& Ryan, R. M. (1985). Intrinsic motivation and self-determination in human behavior. New York: 7 Plenum

Deci, E.L., Koestner, R., \& Ryan, R.M. (2001). Extrinsic Rewards and Intrinsic Motivation in Education: Reconsidered Once Again. Review of Educational Research, 71, 1-27.

Dickinson, L. (1987). Self-instruction in language learning. Cambridge: Cambridge University Press.

Dörnyei, Z. (2001). Teaching and researching motivation. Harlow, UK: Pearson Education Ltd.

Dörnyei, Z., \& Csizér, K. (1998). Ten commandments for motivating language learners: Results of an empirical study. Language Teaching Research 2(3), 203-229.

Dörnyei, Z., \& Ushioda, E. (2013). Teaching and researching: Motivation. Routledge.

Fazey, D. M. A., \& Fazey, J. A. (2001). The potential for autonomy in learning: Perceptions of competence, motivation and locus of control in first-year undergraduate students. Studies in Higher Education, 26(3), 345-361.

Fukuda, S. T., Sakata, H., \& Takeuchi, M. (2011). Facilitating autonomy to enhance motivation: Examining the effects of a guided-autonomy syllabus. Electronic Journal of Foreign Language Teaching, 8(1), 71-86.

Fumin, F., \& Li, Z. (2012). Teachers' roles in promoting students' learner autonomy in China. Canadian Center of Science and Education, 5(4).

Garcia, T., \& Pintrich, P. R. (1996). The effects of autonomy on motivation and performance in the college classroom. Contemporary Educational Psychology, 21, 477-86.

Gardner, R. C. (1990). Attitudes, motivation and personality as predictors of success in foreign language learning. In T. Parry (Ed.), Language aptitude reconsidered (pp. 179221). Englewood Cliffs, NJ: Prentice Hall.

Gardner, R. C. (2006). The socio-educational model of second language acquisition: A research paradigm. EUROSLA Yearbook, 6, 237-260.

Hashemian, M., Heidari Soureshjani, k. (2011). The interrelationship of autonomy, motivation, and academic performance of Persian L2 learners in distance education contexts. Theory and Practice in Language Studies 1(4), 319-326.

Holec, H. (1981). Autonomy in foreign language learning. Oxford: Pergamon.

Hosseini Fahraji, P. (2004). Complexity theory and process paradigm in EFL syllabus design: An action research on learners' autonomy development. Unpublished master's thesis, University of Azzahra, Tehran, Iran.

Isatayeva, G., Samanov, I., Mutanova, D., Aytbayeva, N., Saduova, Z., \& Beisembayeva, S. (2018). Structural relationship between the motivation to study of the second language (De), stability and the second language knowledge. Xlinguae, 11(3), pp.146-157.

Jafari, A. (2002). The effects of authentic materials on the motivation of Iranian preuniversity students. Unpublished master's thesis, University of Alame, Tehran, Iran.

Januin, J. (2007). Exploring readiness for language learning autonomy among distance learners in Sabah. Sabah: Malaysia. 
Kvapil, R. \& Siposova, M. (2020). The crisis of contemporary linguistics vs. applied linguistics. Xlinguae, Vol., 1pp.151-168.

Lepper, M. R., Corpus, J. H., \& Iyengar, S. S. (2005). Intrinsic and extrinsic motivational orientations in the classroom: Age differences and academic correlates. Journal of Educational Psychology, 97, 184-196.

Little, D. (2007). Language learner autonomy: Some fundamental considerations revisited. Innovation in Language Learning and Teaching, 1(1), 14-29.

Liu, H. (2015) Learner Autonomy: The Role of Motivation in Foreign Language Learning. Journal of Language Teaching and Research, 6 (6), 1165-1174.

Ma, Z., \& Ma, R. (2012). Motivating Chinese Students by Fostering Learner Autonomy in Language learning Theory Pract. Lang. Stud. 2. https://doi.org/10.4304/tpls.2.4.838$\underline{842}$.

Masgoret, A. M., \& Gardner, R. C. (2003). Attitudes, motivation, and second language learning: A meta-analysis of studies conducted by Gardner and Associates. Language Learning 53(5), 167-210.

Najeeb, S. S. R. (2013). Learner Autonomy in Language Learning. Procedia - Soc. Behav. Sci., Akdeniz Language Studies Conference, May, 2012, Turkey 70, 1238-1242. https://doi.org/10.1016/j.sbspro.2013.01.183

Nunan, D. (1997). Designing and adapting materials to encourage learner autonomy. In P. Benson \& P. Voller (Eds.), Autonomy and Independence in Language Learning (pp. 192-203). London: Longman.

Oxford, R. L., and Shearin, J. (1994). Language learning motivation: Expanding the theoretical framework. The Modern Language Journal 78(1), 12-28.

Penaflorida, A. H. (2002). Nontraditional forms of assessment and response to student writing: A step toward learner autonomy. In J. C. Richards \& W. A. Renandya (Eds.), Methodology in language teaching: An anthology of current practice (pp. 344-353). Cambridge: Cambridge University Press.

Pintrich, P. R., \& Schunk, D. H. (2002). Motivation in education: Theory, research and applications (2nd ed.). New Jersey: Prentice Hall.

Selivanova,O.G., Gromova, C.R., Mashkin, N.A.(2018).Improving student motivation for learning the second foreign language. Xlinguae, Vol.,1pp.218-229.

Sanprasert, N. (2010). The application of a course management system to enhance autonomy in learning English as a foreign language. System, 38(1), 109-123. https://doi.org/10.1016/j.system.2009.12.010

Snodin, N. S. (2013). The effects of blended learning with a CMS on the development of autonomous learning: A case study of different degrees of autonomy achieved by individual learners. Computers \& Education, 61, 209-216.

Spratt, M., Humphreys, G., \& Chan, V. (2002). Autonomy and motivation: Which comes first? Language Teaching Research, 6, 245-266.

Vaezi, Z. (2008). Language learning motivation among Iranian undergraduate students. World Applied Sciences Journal 5(1), 54-61

Ushioda, E. (1996). Learner Autonomy: The Role of Motivation. Dublin: Authentic Ltd.

Ushioda, E. (2008). Motivation and good language learners' in lessons from good language learners. Cambridge: Cambridge University Press.

Zhang, L.X., \& Li, X.X. (2004). A comparative study on learner autonomy between Chinese students and west European students. Foreign Language World, 4, 15-23. 